\title{
Metabolic myopathy presenting with polyarteritis nodosa: a case report
}

\author{
Sahana Vishwanath, Mishal Abdullah, Amro Elbalkhi and Julian L Ambrus Jr
}

\begin{abstract}
Introduction: To the best of our knowledge, we describe for the first time a patient in whom an unusual metabolic myopathy was identified after failure to respond to curative therapy for a systemic vasculitis, polyarteritis nodosa. We hope this report will heighten awareness of common metabolic myopathies that may present later in life. It also speculates on the potential relationship between metabolic myopathy and systemic vasculitis.
\end{abstract}

Case presentation: A 78-year-old African-American woman with a two-year history of progressive fatigue and exercise intolerance presented to our facility with new skin lesions and profound muscle weakness. Skin and muscle biopsies demonstrated a medium-sized artery vasculitis consistent with polyarteritis nodosa. Biochemical studies of the muscle revealed diminished cytochrome $C$ oxidase activity $(0.78 \mu \mathrm{mol} / \mathrm{minute} / \mathrm{g}$ tissue; normal range 1.03 to $3.83 \mu \mathrm{mol} / \mathrm{minute} / \mathrm{g}$ tissue), elevated acid maltase activity $(23.39 \mu \mathrm{mol} / \mathrm{minute} / \mathrm{g}$ tissue; normal range 1.74 to $9.98 \mu \mathrm{mol} /$ minute/g tissue) and elevated neutral maltase activity $(35.89 \mu \mathrm{mol} / \mathrm{minute} / \mathrm{g}$ tissue; normal range 4.35 to $16.03 \mu \mathrm{mol} / \mathrm{minute} / \mathrm{g}$ tissue). Treatment for polyarteritis nodosa with prednisone and cyclophosphamide resulted in minimal symptomatic improvement. Additional management with a diet low in complex carbohydrates and ubiquinone, creatine, carnitine, folic acid, $\alpha$-lipoic acid and ribose resulted in dramatic clinical improvement.

Conclusions: Our patient's initial symptoms of fatigue, exercise intolerance and progressive weakness were likely related to her complex metabolic myopathy involving both the mitochondrial respiratory chain and glycogen storage pathways. Management of our patient required treatment of both the polyarteritis nodosa as well as metabolic myopathy. Metabolic myopathies are common and should be considered in any patient with exercise intolerance. Metabolic myopathies may complicate the management of various disease states.

\section{Introduction}

Metabolic myopathies are common disorders that are however rarely recognized in adults. They include various mitochondrial myopathies, glycogen storage diseases and disorders of purine metabolism [1,2]. Common presentations in adults may include merely exercise intolerance and muscle weakness with or without pain [3]. Patients with metabolic myopathies clear infections slowly and therefore may be more susceptible to complications of chronic infections.

Polyarteritis nodosa (PAN) is a systemic vasculitis involving medium-sized muscular arteries that has been associated with various chronic infections including hepatitis B, hepatitis $C$ and parvovirus [4,5]. To the best of our knowledge no previous case reports or studies

\footnotetext{
* Correspondence: jambrus@buffalo.edu

Department of Medicine, SUNY at Buffalo School of Medicine, 100 High Street, Buffalo, NY 14203, USA
}

have examined an association between a metabolic myopathy and polyarteritis nodosa.

\section{Case presentation}

A 78-year-old African American woman presented to our facility with a two-year history of progressively worsening fatigue and exercise intolerance. She lived alone and had been independent in her activities of daily living except for two occasions, six months and three months prior to her admission to Buffalo General Hospital, NY, USA, when she was admitted to the hospital for viral syndromes with associated muscle weakness that resolved in five to seven days. She was discharged with a diagnosis of viral syndrome and dehydration. In the three months prior to her admission to Buffalo General Hospital, she had noted progressively worsening muscle weakness and pain, increasing to the point that she was confined to a wheelchair. She had significant abdominal 
pain and intermittent diarrhea. Her medical history was also notable for hypothyroidism, for which she had been treated with levothyroxine replacement for 35 years, and hypertension. Her medications at the time of admission were levothyroxine $125 \mu \mathrm{g}$ daily, atenolol $50 \mathrm{mg}$ daily, aspirin $81 \mathrm{mg}$ daily, calcium $500 \mathrm{mg}$ daily, omeprazole 20 mg daily and a multivitamin. Her physical examination on admission was notable only for diminished muscle strength in the proximal muscles of the lower compared to the upper extremities. There was no known family history of muscle problems. Notable laboratory study results included: white blood cell count $(\mathrm{WBC})=31.6 \times 10^{9}$ cells $/ \mathrm{L}$, hemoglobin $(\mathrm{HGB})=7.7 \mathrm{~g} / \mathrm{dL}$, platelets $=464 \times$ $10^{9}$ cells $/ \mathrm{L}$, aspartate aminotransferase $(\mathrm{AST})=201 \mathrm{U} / \mathrm{L}$, alanine aminotransferase $(\mathrm{ALT})=206 \mathrm{U} / \mathrm{L}$, lactate dehydrogenase $(\mathrm{LDH})=273 \mathrm{U} / \mathrm{L}$, creatine kinase $(\mathrm{CPK})=14$ $\mathrm{U} / \mathrm{L}$, erythrocyte sedimentation rate $(\mathrm{ESR})>150 \mathrm{~mm} /$ hour, C-reactive protein $(\mathrm{CRP})=182 \mathrm{mg} / \mathrm{L}$, ferritin $=$ $10,411 \mathrm{ng} / \mathrm{mL}$, Urinalysis including microscopy was normal, thyroid stimulating hormone $(\mathrm{TSH})=4.27 \mathrm{ulU} / \mathrm{mL}$, free thyroxine $(\mathrm{T} 4)=1.19 \mathrm{ng} / \mathrm{dL}$, positive for cytoplasmic anti-neutrophil cytoplasmic antigen (C-ANCA) (>1:512), negative for perinuclear ANCA (p-ANCA), a negative hepatitis profile, positive for parvovirus IgG (3.9 index; normal: <0.9) and negative for IgM. A computerized tomography (CT) scan of the abdomen showed thickening of the colon consistent with ischemia and muscle biopsy showed vasculitis involving muscular arteries and arterioles consistent with polyarteritis nodosa. Treatment was initiated with prednisone $60 \mathrm{mg}$ daily and cyclophosphamide $150 \mathrm{mg}$ daily. After two weeks of therapy, minimal clinical improvement was noted, although her inflammatory parameters had decreased $(\mathrm{WBC}=3.8 \times$ $10^{9}$ cells $/ \mathrm{L}, \mathrm{HGB}=10.3 \mathrm{~g} / \mathrm{dL}$, platelets $=262 \times 10^{9}$ cells $/$ $\mathrm{L}, \mathrm{ESR}=50 \mathrm{~mm} /$ hour, $\mathrm{CRP}=22 \mathrm{mg} / \mathrm{L}, \mathrm{AST}=47 \mathrm{U} / \mathrm{L}$, Alt $=23 \mathrm{U} / \mathrm{L}$, and ferritin $=2567 \mathrm{ng} / \mathrm{mL}$ ). Biochemical studies became available that demonstrated a defect in the mitochondrial respiratory chain with a low cytochrome c oxidase level of $0.78 \mu \mathrm{mol} / \mathrm{minute} / \mathrm{g}$ tissue (normal range: 1.03 to $3.83 \mu \mathrm{mol} / \mathrm{minute} / \mathrm{g}$ tissue), and evidence of a lysosomal defect resulting in a secondary glycogen storage disease with elevated acid maltase level $23.39 \mu \mathrm{mol} / \mathrm{minute} / \mathrm{g}$ tissue (normal range: 1.74 to 9.98 $\mu \mathrm{mol} / \mathrm{minute} / \mathrm{g}$ tissue) and neutral maltase level 35.89 $\mu \mathrm{mol} / \mathrm{minute} / \mathrm{g}$ tissue (normal range: 4.35 to $16.03 \mu \mathrm{mol} /$ minute/g tissue). Our patient was treated with a diet free of complex carbohydrates and a compound containing ubiquinone, creatine, carnitine, folic acid, $\alpha$-lipoic acid and ribose, resulting in slow clinical improvement over the next several months.

\section{Discussion}

We present the case of a patient with a complex metabolic disorder involving defects in enzymes of the mitochondrial respiratory chain and glycogen storage pathways who developed a systemic vasculitis, resulting in a need for acute medical attention. Treatment of the vasculitis resulted in improvement in laboratory parameters but not in clinical symptoms. Symptomatic improvement occurred with additional management of the complex metabolic disease.

Several metabolic diseases are known to present in adulthood and to be common in the general population. Myoadenylate deaminase deficiency affects approximately $5 \%$ of the population, myophosphorylase deficiency, a glycogen storage disease, affects $8 \%$ of the population and various mitochondrial disorders exist in between $1: 1000$ to $1: 10,000$ of the population, depending upon various estimates $[1,6-8]$. Our patient had a mitochondrial respiratory chain defect along with an unusual glycogen storage defect with high levels of lysosomal acid and neutral maltase, likely resulting in reduced cytosolic levels of these enzymes. It is possible that the mitochondrial defect resulted from inadequately replaced hypothyroidism, but there is no data to support this hypothesis and our patient's thyroid studies were normal at the time of admission [9]. The manifestations of these metabolic diseases in an adult are often merely exercise intolerance and fatigue, which were getting worse in our patient over a period of two years [1]. At the same time, patients with metabolic diseases often have difficulty clearing infections, and our patient had two admissions for worsening muscle symptoms because of viral infections even before the onset of her vasculitis [10]. Interestingly, our patient did have positive IgG serology results for parvovirus, which has been associated with polyarteritis nodosa $[5,11]$. It is possible that difficulty with clearing parvovirus led to immune complex formation and secondary vasculitis, although there was no evidence of ongoing parvovirus infection at her time of admission to Buffalo General Hospital.

The manifestations of polyarteritis nodosa in our patient were muscle pain and weakness, abdominal pain and elevated inflammatory markers including ESR, CRP, ferritin and platelets. She had a positive C-ANCA result that is most commonly associated with Wegener granulomatosis but can certainly be seen in polyarteritis nodosa as well [12]. Our patient had a clinical picture and muscle biopsy supporting a diagnosis of polyarteritis nodosa but not Wegener granulomatosis. Interestingly, treatment for polyarteritis nodosa, high-dose steroids and cyclophosphamide, resulted in improvement in inflammatory parameters with resolution of abdominal symptoms, but not muscle weakness. Improvement in muscle weakness occurred over a period of months with management of the metabolic disease.

The management of mitochondrial dysfunction is currently under investigation, but several approaches have 
been shown to be fruitful. Supplementing with ubiquinone (CoQ10), which transports electrons between complex I and complex III of the mitochondrial respiratory chain, has been shown to improve mitochondrial function in several studies [13]. Creatine is utilized to generate additional ATP through the creatine phosphate shuttle [14]. Carnitine is added to enhance transport of fatty acids into the mitochondria. Folic acid is a cofactor for several mitochondrial enzymes. $\alpha$-Lipoic acid is a strong antioxidant [15]. In the management of glycogen storage diseases, complex carbohydrates are avoided and simple sugars, such as ribose, are utilized to provide a more available energy source $[3,16]$. This strategy resulted in significant symptomatic improvement in our patient.

It has recently been noted that patients who have inflammatory muscle diseases that do not respond to immunosuppressive therapies as expected often have underlying metabolic muscle diseases. This is the first documented case of a vasculitis with incomplete clinical response to immunosuppressive therapy in which the management of a complex metabolic disorder was necessary for symptomatic relief $[17,18]$. This case should alert physicians to include various common adult onset metabolic disorders in the investigation of symptom complexes including fatigue and various muscle problems.

\section{Conclusions}

To the best of our knowledge, this report describes for the first time a patient in which symptomatic improvement of a systemic vasculitis required the simultaneous management of a metabolic myopathy. Since metabolic myopathies are common, they should always be considered when inflammatory diseases are not responding to standard therapies as expected.

\section{Consent}

Written informed consent was obtained from the patient for publication of this case report and any accompanying images. A copy of the written consent is available for review by the Editor-in-Chief of this journal.

\section{Authors' contributions}

All authors participated in the care of our patient and the writing of this manuscript. All authors read and approved the final manuscript.

\section{Competing interests}

The authors declare that they have no competing interests.

Received: 7 January 2011 Accepted: 30 June 2011

Published: 30 June 2011

\section{References}

1. Berardo A, DiMauro S, Hirano M: A diagnostic algorithm for metabolic myopathies. Curr Neurol Neurosci Rep 2010, 10:118-126.
2. Di Donato S: Multisystem manifestations of mitochondrial disorders. $J$ Neurol 2009, 256:693-710.

3. Burra ML, Roos JC, Ostor AJK: Metabolic myopathies: a guide and update for clinicians. Curr Opin Rheumatol 2008, 20:639-647.

4. Cohen P, Guillevin L: Vasculitis associated with viral infections. Presse Medicale 2004, 33:1371-1384.

5. Pagnoux C, Cohen P, Guillevin L: Vasculitides secondary to infections. Clin Exp Rheumatol 2006, 24:S71-S81.

6. Angelini C, Semplicini C: Metabolic myopathies: the challenge of new treatments. Curr Opin Pharmacol 2010, 10:338-345

7. Teijeira S, Millan BS, Fernandez JM, Rivas E, Vieitez I, Miranda S, Gonzalez F, Navarro C: Myoadenylate deaminase deficiency: clinico-pathological and molecular study of a series of 27 Spanish cases. Clin Neuropathol 2009, 28:136-142.

8. Wallace DC: Mitochondrial DNA mutations in disease and aging. Environ Mol Mutagen 2010, 51:440-450.

9. Harper ME, Seifert EL: Thyroid hormone effects on mitochondrial energetics. Thyroid 2008, 18:145-156.

10. Arnoult D, Carneiro L, Tattoli I, Girardin SE: The role of mitochondria in cellular defense against microbial infection. Semin Immunol 2009, 21:223-232.

11. Magro CM, Crowson AN, Dawood M, Nuovo GJ: Parvoviral infection of endothelial cells and its possible role in vasculitis and autoimmune diseases. J Rheumatol 2002, 29:1227-1235.

12. Ito Y, Nishi A, Sakaguchi M, Suzuki Y, Kaneko K, Yasuoka C, Tomita S, Kato H: Anti-neutrophil cytoplasmic antibody for proteinase 3 in a child with polyarteritis nodosa. Acta Paediatr Jpn 1995, 37:116-119.

13. Haas $\mathrm{RH}$ : The evidence basis for coenzyme $\mathrm{Q}$ therapy in oxidative phosphorylation disease. Mitochondrion 2007, 7(Suppl):S136-145.

14. Adhihetty PJ, Beal MF: Creatine and its potential therapeutic value for targeting cellular energy impairment in neurodegenerative diseases. Neuromol Med 2007, 10:275-290.

15. Tarnopolsky MA: The mitochondrial cocktail: rationale for combined nutraceutical therapy in mitochondrial cytopathies. Adv Drug Deliv Rev 2008, 60:1561-1567.

16. Quinlivan RM, Beynon RJ: Pharmacological and nutritional treatment trials in McArdle disease. Acta Myol 2007, 26:58-60.

17. Temiz P, Weihl CC, Pestronk A: Inflammatory myopathies with mitochondrial pathology and protein aggregates. J Neurol Sci 2009, 278:25-29.

18. Varadhachary AS, Weihl CC, Pestronk A: Mitochondrial pathology in immune and inflammatory myopathies. Curr Opin Rheumatol 2010, 22:651-657.

doi:10.1186/1752-1947-5-262

Cite this article as: Vishwanath et al:: Metabolic myopathy presenting with polyarteritis nodosa: a case report. Journal of Medical Case Reports 2011 5:262.

\section{Submit your next manuscript to BioMed Central and take full advantage of:}

- Convenient online submission

- Thorough peer review

- No space constraints or color figure charges

- Immediate publication on acceptance

- Inclusion in PubMed, CAS, Scopus and Google Scholar

- Research which is freely available for redistribution

Submit your manuscript at www.biomedcentral.com/submit
C BioMed Central 